\title{
Menjaga Eksistensi Pelestarian Bahasa Sampit di Masa Pandemi Bersama Lembaga Adat dan Budaya Sampit
}

\author{
Sandy Ramadhan ${ }^{1}$, Fauzi $^{2}$, Nur Aida ${ }^{3}$, Dwi Maulina Permata Sari ${ }^{4}$, Gita Anggraini ${ }^{5}$ \\ ${ }^{1}$ Pendidikan Matematika, Pendidikan, STKIP Muhammadiyah Sampit \\ ${ }^{2}$ Bimbingan dan Konseling, Pendidikan, STKIP Muhammadiyah Sampit \\ ${ }^{3}$ Pendidikan Bahasa Inggris, Pendidikan, STKIP Muhammadiyah Sampit \\ ${ }^{4}$ Pendidikan Ekonomi, Pendidikan, STKIP Muhammadiyah Sampit \\ ${ }^{5}$ Bimbingan dan Konseling, STKIP Muhammadiyah Sampit \\ Email: sandyramadhan59@gmail.com
}

\begin{abstract}
Abstrak
Bahasa Sampit merupakan salah satu bahasa daerah di Indonesia yang statusnya saat ini terancam. Saat ini bahasa Sampit mulai jarang dituturkan, bahkan dikenal masyarakat dan hanya digunakan sebagian generasi tua saja. Pengabdian melalui Program Kreativitas Mahasiswa (PKM) bertujuan untuk membantu Lembaga Adat dan Budaya Sampit dalam melestarikan bahasa Sampit melalui pembuatan kamus bahasa Sampit. Kegiatan ini dilaksanakan metode yang terdiri dari 3 (tiga) tahapan, yaitu tahap awal, tahap inti, dan tahap akhir yang dilaksanakan dalam waktu 2 (dua) bulan. Hasil dari pelaksanaan kegiatan ini yaitu telah terinventarisasi dan terkategorinya kosakata bahasa Sampit sejumlah 1836 kosakata dalam sebuah database, terbentuknya tim perumus bahasa Sampit, terjalinnya kerjasama dengan Balai Bahasa Kalimantan Tengah, dan bahasa Sampit diangkat menjadi program revitalisasi bahasa oleh Balai Bahasa Kalimantan Tengah. Sehingga akan terus terjaga eksistensi pelestarian Bahasa Sampit bersama Lembaga adat dan budaya Sampit.
\end{abstract}

Kata Kunci: Bahasa Sampit, Lembaga Adat dan Budaya Sampit, dan Bahasa Daerah

\begin{abstract}
The Sampit language is one of the regional languages in Indonesia whose status is currently under threat. Currently, the Sampit language is rarely spoken, it is even known to the public and is only used by some of the older generations. Community service through the Student Creativity Program (PKM) aims to assist Sampit's Customary and Cultural Institutions in preserving the Sampit language by making a Sampit language dictionary. This activity is carried out in a method consisting of 3 (three) stages, namely the initial stage, the core stage, and the final stage which are carried out within 2 (two) months. The results of this activity were inventoried and categorized the vocabulary of the Sampit language as many as 1836 words in a database, the formation of the Sampit language drafting team, the collaboration with the Central Kalimantan Language Center, and the Sampit language being appointed as a language revitalization program by the Central Kalimantan Language Center. So that the existence of the Sampit language preservation will be maintained with the Sampit traditional and cultural institutions.
\end{abstract}

Keywords: Sampit Language, Sampit Cultural and Traditional Institutions, and Local Languages 


\section{PENDAHULUAN}

Bahasa Dayak Sampit sebagai salah satu bahasa daerah di Indonesia, merupakan salah satu bahasa yang saat ini terancam. Jika menggunakan tipologi yang dikemukakan Krauss (1992), bahasa Dayak Sampit dapat dikategorikan dalam endangered languages (bahasabahasa yang terancam punah). Krauss menyebutnya juga dengan bahasa yang tidak bugar, dengan ciri: hanya digunakan oleh penutur yang berusia 25 tahun ke atas. Sedangkan penutur yang berusia 25 tahun ke bawah tidak lagi menggunakannya secara aktif. Krauss mengasumsikan, jika tidak ada gerakan penyadaran maka dalam 50 tahun ke depan bahasa ini akan benar-benar punah (Anggraini, 2019).

Bahasa Sampit merupakan bahasa asli masyarakat Kota Sampit, Kabupaten Kotawaringin Timur, Kalimantan Tengah. Bahasa Dayak Sampit merupakan sub dialek dari rumpun Bahasa Dayak. Bahasa ini memiliki karakteristik tersendiri yang membedakannya dari bahasa Dayak lainnya. Dalam tatanan sosial budaya, bahasa Sampit dianggap lebih halus (lembut) dari bahasa Dayak yang ada di Kalimantan Tengah. Hal ini dibuktikan dengan adanya tingkatan kosa kata dalam kata ganti orang sesuai umur atau status sosial (Winarti, Ramadhan, \& Rahmawati, 2019).

Saat ini bahasa Sampit mulai jarang dituturkan, hanya sebagian tempat yang masih aktif menggunakan bahasa Sampit, seperti Desa Tinduk, Terantang, Kecamatan Kota Besi, sebagian kecil di Kecamatan Baamang, Mentawa Baru Ketapang, Kecamatan Cempaga, dan beberapa perkampungan yang menyebar di beberapa kecamatan lainnya. Rata-rata yang masih aktif menggunakan bahasa Sampit berasal dari generasi tua, sedangkan generasi muda mayoritas menggunakan bahasa Banjar. Tidak adanya rujukan baku untuk belajar bahasa Sampit menjadi salah satu faktor sulitnya belajar bahasa Sampit.

Sebenarnya ada sebuah organisasi yang dibentuk untuk melestarikan budaya Sampit, termasuk bahasanya yaitu Lembaga Adat dan Budaya Sampit. Lembaga ini memiliki program kerja yaitu untuk membuat sebuah kamus baku bahasa Sampit. namun, karena minimnya biaya, waktu dan dasar keilmuan, serta tidak adanya tim penggerak untuk membuat kamus bahasa Sampit yang menyebabkan program tersebut tidak dapat direalisasikan.

Dengan adanya kegiatan ini program kerja tersebut sudah mulai direalisasikan. Salah satunya adalah Lembaga Adat dan Budaya Sampit yang semula tidak mengetahui tentang pembuatan kamus, kini telah mengetahui apa saja tahapan-tahapan yang perlu dilakukan, serta bagaimana teknis dalam pembuatan kamus yang diperoleh melalui pengarahan dan pendampingan dari Balai Bahasa Kalimantan Tengah. Lembaga adat dan Budaya Sampit juga membentuk Tim perumus dalam pembuatan Kamus Bahasa Sampit agar mempermudah dalam melakukan penyelarasan, pengkajian, penyusunan, dan penyempurnaan kamus yang saat ini Kosakata Bahasa Sampit yang sudah terinventarisasi serta terkategorinya sesuai kelas katanya yang dimuat dalam sebuah database. Sehingga upaya dalam menjaga eksistensi bahasa Sampit. Melalui kegiatan ini, program kerja Lembaga Adat dan Budaya Sampit yang berupa pembuatan kamus bahasa Sampit dapat terealisasikan. Walaupun pelaksanaan kegiatan di masa pandemi Coronavirus Disease 2019 (COVID-19) membawa banyak perubahan, termasuk perubahan kegiatan pengabdian masyarakat upaya pelestarian bahasa Sampit menjadi terbatas dan dilaksanakan secara daring itu tidak menjadi penghambat untuk menjaga eksistensi pelestarian bahasa sampit di masa pandemi bersama lembaga adat dan budaya sampit 


\section{METODE}

Pengabdian masyarakat ini merupakan kegiatan Program Kreativitas Mahasiswa (PKM) yang dilaksanakan selama 2 bulan sejak Agustus sampai dengan Oktober tahun 2020. Tempat pelaksanaan kegiatan di Sampit, Kabupaten Kotawaringin Timur Kalimantan Tengah. Kegiatan difokuskan secara daring dengan memanfaatkan beberapa aplikasi dan media sosial. Adapun aplikasi yang dimaksud adalah Zoom Meeting, Instagram, dan WA Group.

Tim pelaksana adalah kelompok mahasiswa yang menjalankan program kreativitas mahasiswa pengabdian masyarakat dari STKIP Muhammadiyah Sampit. Kelompok ini terdiri dari empat orang mahasiswa yang didampingi oleh seorang dosen pembimbing.

Adapun tahapan pelaksanaan dapat dilihat pada tabel/ bagan berikut:

1. Tahap awal adalah tahap perencanaan dan persiapan pelaksanaan program. Pada tahap awal dilakukan penyesuaian program dari luring menjadi daring. Selain itu, pada tahap

Tahap Awal

Penyesuaian Program Menjadi Daring Menjalin Kerjasama dengan Balai Bahasa Kalimantan Tengah

\section{Tahap Inti}

Pengarahan dari Balai Bahasa

Kalimantan Tengah

Pembuatan Buku Pedoman

Pelaksanaan Program

Seminar Daring

Pendampingan Penyusunan

Kamus dari Balai Bahasa

Kalteng (daring)

Inventarisasi dan

Mengategorikan Kosakata

Pendampingan Balai Bahasa

Kalteng Tahap II (daring)

Validasi Data

Pendampingan Balai Bahasa

Kalteng Tahap III (daring)

\section{Gambar 1. Tahapan Awal}

2. ini terjalin kerjasama antara Balai Bahasa Kalimantan Tengah, Lembaga Adat dan Budaya Sampit, dan tim pelaksana.

3. Tahap inti terdiri dari beberapa kegiatan, yaitu pertama, pengarahan dari Balai Bahasa Kalimantan Tengah mengenai tahapan-tahapan yang harus dilakukan dalam penyusunan kamus bahasa Sampit. Kedua, penyusunan buku pedoman pelaksanaan yang dapat menjadi acuan Lembaga Adat dan Budaya Sampit agar mengetahui tahapan dalam penyusunan kamus bahasa Sampit. Ketiga, pelaksanaan seminar daring dengan tema "Urgensi Kamus Untuk Menjaga Eksistensi Bahasa Sampit". Keempat, pendampingan penyusunan kamus oleh Balai Bahasa Kalimantan Tengah. Dalam kegiatan ini tim pelaksana menjadi fasilitator yang menyediakan akses bagi Lembaga Adat dan Budaya Sampit untuk mendapatkan pendampingan dari Balai Bahasa Kalimantan Tengah. Kelima, inventarisasi dan mengkategorikan kosakata yang dilakukan oleh tim pelaksana dan Lembaga Adat dan Budaya Sampit secara bersama-sama. Keenam, validasi data yang 
dilakukan untuk memastikan kosakata yang telah terkumpul adalah kosakata yang benarbenar bahasa Sampit, serta benar dalam penerjemahan.

4. Tahap akhir dari kegiatan adalah evaluasi program dan penyusunan laporan akhir kegiatan.

\section{HASIL}

Sejak pelaksanaan pengabdian beberapa hasil telah dicapai sehingga dapat membantu masyarakat sasaran (Lembaga Adat dan Budaya Sampit) dalam menyelesaikan program kerja organisasinya. Secara lebih rinci hasil yang dicapai adalah sebagai:

1. Terbentuknya tim perumus kamus bahasa sampit yang terdiri dari Lembaga Adat dan Budaya Sampit, tim pelaksana dan didampingi oleh Balai Bahasa Kalimantan Tengah. Tim perumus dibentuk agar mempermudah dalam melakukan penyelarasan, pengkajian, penyusunan, dan penyempurnaan kamus.

2. Terjalinnya kerjasama yang baik dengan Balai Bahasa Kalimantan Tengah. Kerjasama dijalin dengan dilakukannya komunikasi intens dan pendampingan oleh Balai Bahasa Kalimantan Tengah dalam beberapa kegiatan penyusunan kamus bahasa Sampit. kegiatan-kegiatan tersebut, yaitu seminar daring urgensi pembuatan kamus, pendampingan dan pengarahan penyusunan kamus, serta diskusi mengenai tahapantahapan penyusunan kamus.

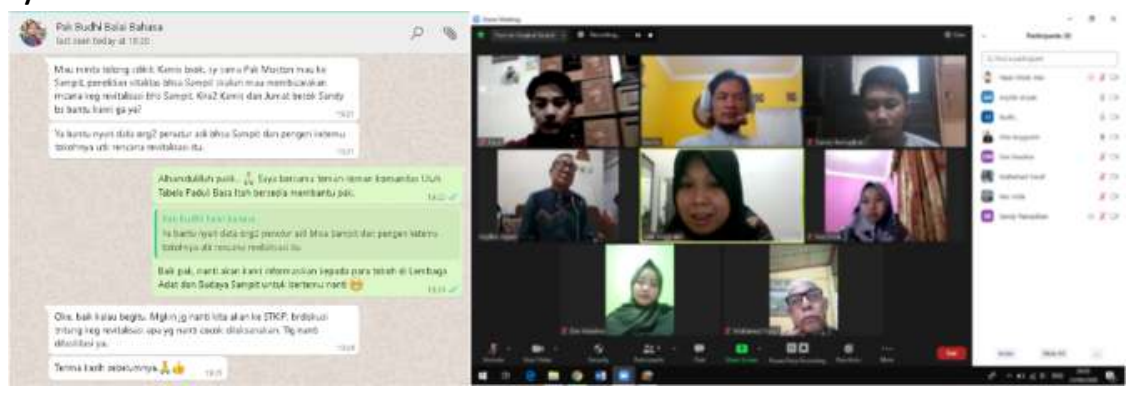

\section{Gambar 2. Kerjasama Balai Bahasa Kalimantan Tengah dengan Tim Pelaksana dan Lembaga Adat dan Budaya Sampit}

3. Seminar daring dengan tema "Urgensi Kamus Untuk Menjaga Eksistensi Bahasa Sampit" yang diikuti oleh Lembaga Adat dan Budaya Sampit, tim pelaksana dan masyarakat yang peduli akan bahasa Sampit. Kegiatan seminar daring bertujuan untuk mengetahui bagaimana teknis dalam pembuatan kamus secara umum.

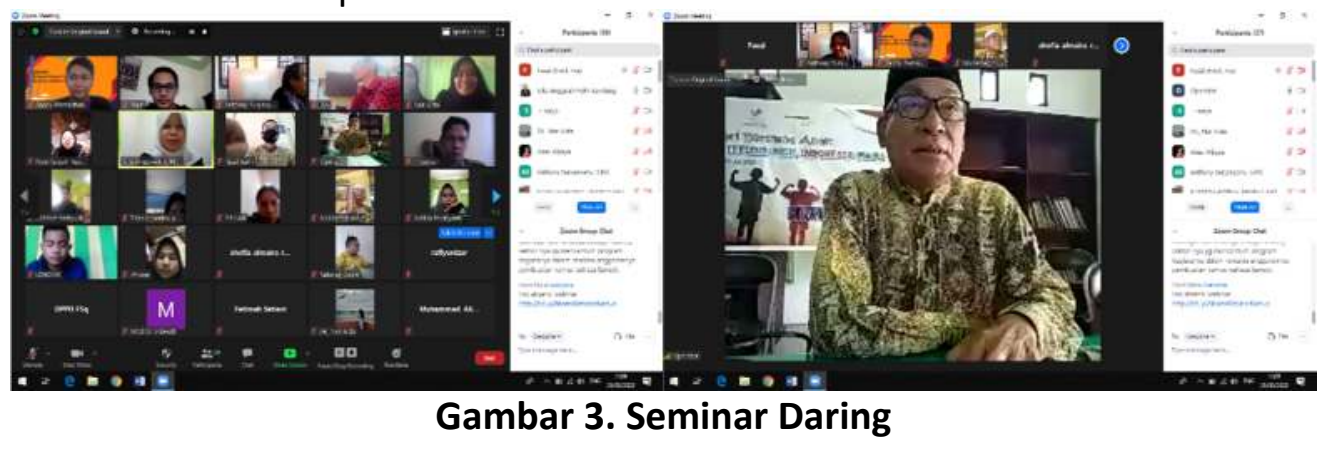

Urgensi Kamus Untuk Menjaga Eksistensi Bahasa Sampit

4. Terinventarisasi dan terkategorisasinya kosakata bahasa Sampit sebanyak 1837 kata dalam sebuah database. Kosakata tersebut merupakan kosakata gabungan yang telah dikumpulkan. Setelah kosakata digabungkan, dilakukan penyaringan terhadap kosakata 
yang sama dan diinventarisasi, serta pengaktegorian kosakata sesuai dengan kelas katanya.

\begin{tabular}{|c|c|c|c|}
\hline \multicolumn{2}{|c|}{$A$} & \multirow{2}{*}{ Ilut borjuang } & \multirow[b]{2}{*}{ Ungkapan an } \\
\hline 1817 & Umpat bajuang & & \\
\hline 1818 & Umpat bssahokan & Ihut bersembuny? & Kalmat pendek \\
\hline 1819 & Utrpat kula & Ikut saya & Kalinat pendek \\
\hline 1820 & Uxipat kuman & Ilnat makan & Kalinat pendek \\
\hline 1821 & Umpat maneser & Itat menyelom & Kalimat pendek \\
\hline 1022 & Utrpat maryelek & Ihut nengintip & Kalinat pendek. \\
\hline 1823 & Undus & Minyak Kelapa & Notrina (Kata Benda) \\
\hline 1824 & Upoh & Goji & Notrina (Kata Benda) \\
\hline 1825 & Upak & Kulit & Nonins (Kata Benda) \\
\hline 1826 & Unu & Rusnout & Kata benda \\
\hline 1827 & Us ang & Usang, lrumel & Adjeitiva (Kata Sifat) \\
\hline 1828 & Usus kanai & Usus & Nomans (Kata Benda) \\
\hline 1829 & Uwe & Kakek & Kats ganti \\
\hline 1850 & Uyah & Garam & Nottina (Kata Benda) \\
\hline 1831 & Wadas & Kus & Nomino (Kata Benda) \\
\hline 1832 & Wadi & Pengawetan ikar/daging & \\
\hline 1833 & Watas & Batas & Nottina (Kata Benda) \\
\hline 1834 & waylah tin & Sant ins & \\
\hline 1835 & Wayah-Wayah & Kadang-Kadang & Adverbia (Kata Keterangan) \\
\hline 1036 & Yalku & Soya (Kepada yang muda/se untur & Pronoriaria \\
\hline 1937 & & & \\
\hline
\end{tabular}

Gambar 4. Kosakata Bahasa Sampit

5. Bahasa Sampit diangkat sebagai program revitalisasi oleh Balai Bahasa Kalimantan Tengah. Kerjasama yang terus berlanjut menjadikan bahasa Sampit diangkat sebagai program revitalisasi untuk yang pertama kalinya.

6. Buku pedoman pelaksanaan kegiatan yang berisi tahapan-tahapan penyusunan kamus bahasa Sampit.

\section{PEMBAHASAN}

Pandemi Covid-19 membawa banyak perubahan, seperti pelaksanaan dan luaran kegiatan. Hal ini menyebabkan kegiatan yang semula direncanakan untuk dilaksanakan secara luring diadaptasi menjadi daring. Selain itu, karena keterbatasan waktu dan kondisi pandemi saat ini, luaran kegiatan yang semula merupakan sebuah kamus baku kemudian diadaptasikan menjadi database kosakata bahasa Sampit yang telah terorganisasi dan terkategori sesuai dengan kelas katanya.

Walaupun kegiatan dilaksanakan secara daring, kegiatan ini tetap membantu masyarakat sasaran, yaitu Lembaga Adat dan Budaya Sampit dalam merealisasikan program kerjanya. Kegiatan ini menjadi jalan pembuka bagi Lembaga Adat dan Budaya Sampit untuk menjalin kerjasama dengan Balai Bahasa Kalimantan Tengah dalam pembuatan kamus bahasa Sampit. Hal ini ditandai dengan adanya pendampingan dari Balai Bahasa Kalimantan Tengah. Selain itu, melalui kegiatan ini dapat di kumpulan kosakata bahasa Sampit yang berupa database yang lebih kaya dan terorganisasi.

Pada awalnya, program kerja dari Lembaga Adat dan Budaya Sampit belum terealisasikan karena adanya beberapa alasan, salah satunya adalah kurangnya dasar keilmuan mengenai pembuatan kamus. Namun, dengan adanya kegiatan ini program kerja tersebut sudah mulai berjalan. Salah satunya adalah Lembaga Adat dan Budaya Sampit yang semula tidak mengetahui tentang pembuatan kamus, kini telah mengetahui apa saja tahapantahapan yang perlu dilakukan, serta bagaimana teknis dalam pembuatan kamus yang diperoleh melalui pengarahan dan pendampingan dari Balai Bahasa Kalimantan Tengah. 
Sebelum adanya kegiatan ini, Lembaga Adat dan Budaya Sampit belum memiliki tim perumus bahasa Sampit, dan bahasa Sampit dikhawatirkan karena mulai memudar seiring perkembangan zaman. Namun melalui kegiatan ini, terbentuk tim perumus bahasa Sampit yang terdiri dari Lembaga Adat dan Budaya Sampit dan tim pelaksana yang didampingi oleh Balai Bahasa Kalimantan Tengah. Selain itu, melalui kegiatan ini bahasa Sampit menjadi program revitalisasi yang merupakan program kerja dari Balai Bahasa Kalimantan Tengah tahun anggaran 2020.

Lembaga Adat dan Budaya Sampit selaku masyarakat sasaran merasa sangat terbantu dengan adanya kegiatan ini. Karena, melalui kegiatan ini program kerja berupa pembuatan kamus bahasa Sampit mulai terealisasi. Selain itu, Lembaga Adat dan Budaya Sampit memiliki akses berkomunikasi dengan Balai Bahasa Kalimantan Tengah yang memudahkan dalam proses pembuatan kamus bahasa Sampit.

Jadi, kegiatan ini adalah upaya dalam menjaga eksistensi bahasa Sampit. Melalui kegiatan ini, program kerja Lembaga Adat dan Budaya Sampit yang berupa pembuatan kamus bahasa Sampit dapat terealisasikan dan dengan terealisasikannya program kerja tersebut, maka terdapat rujukan bagi masyarakat dalam belajar bahasa Sampit. Sehingga, bahasa Sampit tidak memudar dan menghilang seiring berjalannya perkembangan zaman.

\section{PENUTUP}

\section{Kesimpulan}

Kamus merupakan suatu rujukan dalam memperkaya dan memperluas perbendaharaan kata. Selain itu, kamus merupakan suatu upaya dalam menjaga bahasa Sampit yang semakin memudar seiringnya perkembangan zaman. Program ini telah berhasil menjalin kerjasama dengan Balai Bahasa Kalimantan Tengah sehingga bahasa Sampit diangkat menjadi program revitalisasi bahasa tahun anggaran 2020, terlaksananya seminar daring tentang urgensi kamus untuk menjaga eksistensi bahasa, terinventarisasi dan terkategorisasinya kosakata bahasa Sampit, tercipta buku pedoman pelaksanaan program yang memperoleh HaKI, dan terpublikasinya kegiatan dari media cetak maupun online.

\section{Saran}

Beberapa yang perlu disarankan adalah pemerintah harus melakukan tindak lanjut mengenai kamus bahasa Sampit agar kamus tersebut dapat menjadi literatur dan akses bagi masyarakat untuk mempelajari bahasa Sampit.

\section{UCAPAN TERIMAKASIH}

Selesainya program ini dengan hasil sesuai yang diharapkan merupakan anugerah dari Allah SWT, Tuhan Yang Maha Esa. Tidak lupa pula ucapan terima kasih kami haturkan kepada berbagai pihak yang telah mendukung program ini, diantaranya yaitu:

a. Kementerian Pendidikan dan Kebudayaan yang telah memberikan kesempatan dan memberikan pendanaan;

b. STKIP Muhammadiyah Sampit yang telah mendukung, mengayomi dan memberikan arahan selama pelaksanaan program;

c. Dosen pendamping yang telah memberikan bimbingan, arahan, masukan dan mengayomi selama pelaksanaan program;

d. Lembaga Adat dan Budaya Sampit;

e. Media massa elektronik dan cetak yang telah membantu publikasi dan penyebarluasan informasi; serta

f. Seluruh pihak yang telah mendukung terselenggaranya program ini. 


\section{DAFTAR PUSTAKA}

Anggraini, G. (2019). Konservasi Bahasa Melalui Program Kreativitas Mahasiswa. Dalam S. Ramadhan, Fauzi, Berniati, D. M. Sari, N. Sari, J. Sari, et al., Kata Milenial tentang Bahasa Sampit (hal. 73). Pangkalan Bun: Cangkir Pustaka.

Winarti, Ramadhan, S., \& Rahmawati. (2019). Bakesah: Uluh Tabela Manokep Bahasa Sampit (Kompilasi Data Seputar Bahasa Sampit dan Kandungan Nilai Karakternya). (G. Anggraini, Penyunt.) Pangkalan Bun: Tjangkir Poestaka. 